\title{
Correction to: Skin Care Prevention: Psychosocial Predictors of Sunscreen Use in University Students
}

\author{
Mehdi Mirzaei-Alavijeh $^{1} \cdot$ Hassan Gharibnavaz ${ }^{1} \cdot$ Farzad Jalilian $^{1}$
}

Published online: 4 December 2019

(C) American Association for Cancer Education 2019

\section{Correction to: Journal of Cancer Education}

https://doi.org/10.1007/s13187-019-01579-2

The article Skin Cancer Prevention: Psychosocial Predictors of Sunscreen Usein University Students, written by Mehdi Mirzaei-Alavijeh, Hassan Gharibnavaz and Farzad Jalilian, was originally published electronically on the publisher's internet portal (currently SpringerLink) on July 23, 2019 with open access. With the author(s)' decision to step back from Open Choice, the copyright of the article changed on November 2019 to (C) American Association for Cancer Education 2019 and the article is forthwith distributed under the terms of copyright.

The original article has been corrected.

Publisher's Note Springer Nature remains neutral with regard to jurisdictional claims in published maps and institutional affiliations.

The online version of the original article can be found at https://doi.org/ $10.1007 / \mathrm{s} 13187-019-01579-2$

Farzad Jalilian

f_jalilian@yahoo.com

1 Social Development \& Health Promotion Research Center, Health Institute, Kermanshah University of Medical Sciences,

Kermanshah, Iran 